\title{
Breast Cancer in Special Situations
}

\author{
Bernd Gerber \\ Breast Unit, Department of Obstetrics and Gynecology, University of Rostock, Germany
}

Diagnosis and therapy of breast cancer in women are based on randomized clinical trials and determined by consensus conferences, and in recommendations and guidelines [1-4]. However, special situations like breast cancer during pregnancy, in elderly patients, in male patients and carcinomas of unknown primary with first manifestation in the axillary lymph nodes as well as rare histological types of breast tumors are infrequent and mostly excluded in guidelines. Common to all of these 'special situations' is that:

- each of us will see only very few cases during their professional life,

- these rare diseases are frequently not considered in differential diagnosis,

- diagnosis and treatment are not standardized,

- there are no randomized clinical trials and none will be available in the near future,

- although we believe to do the best for our patients, underor overtreatment are very frequent.

The focus in this issue of BREAST CARE contains review articles dealing with 'special situations' in the diagnosis and treatment of breast malignancies. The current knowledge of carcinomas of unknown primary (CUP) leaves many open questions. For example, which diagnostic procedures are indicated in metastatic involvement of axillary lymph nodes with negative mammography and ultrasound? Magnetic resonance imaging (MRI) of the breast enables identification of an occult breast primary tumor in up to $80 \%$ of women who display adenocarcinoma in the axillary lymph nodes [5, 6]. Moreover, is MRI the standard or should one better start with positron emission tomography (PET) scan today [7]? Which primary tumor locations are possible and which perioperative staging examinations are necessary? Also, the appropriate treatment of the breast after an axillary presentation of CUP continues to be a controversial issue. Furthermore, is there an indication for mastectomy and/or mammary irradiation if mammary
MRI is negative? Is the management of axillary lymph node metastases in women with CUP the same as for patients with breast cancer? Finally, one has to ask about the systemic treatment. Alwin Krämer and colleagues tried to give answers to all these questions about CUP in general and in specific situations, such as unilateral axillary lymph node involvement [8]. The next review by Sibylle Loibl deals with the increasing problem of breast cancer in pregnancy [9]. With an increase in average age of pregnant women, the coincidence of a breast cancer diagnosis with the patient also being pregnant or nursing has become more frequent. This fact urgently needs to be acknowledged by physicians since the diagnosis of breast cancer is frequently delayed in pregnancy. As a consequence, it is not only recommended that pregnant or nursing women should examine their breast on a regular basis but also that clinical examination of breasts and loco-regional lymph nodes should be part of a routine medical care during pregnancy and nursing period. Moreover, S. Loibl states that also in pregnancy or the nursing period breast imaging (breast ultrasound, mammography) and biopsy should be performed as in nonpregnant patients. Regarding therapy recommendations for pregnant women, Loibl points out some important exceptions, for example, chemotherapy is only possible after the 12th week of pregnancy, therapeutic radiation during pregnancy is contraindicated, and there should be a three-week interval between the last chemotherapy cycle and delivery, since the risk of maternal delivery-associated complications is increased and the newborn may not be able to metabolize potential chemotherapy remainders [2].

It is estimated that worldwide nearly one third of breast cancer patients are older than 65 years. In more developed countries this proportion even rises to more than $40 \%$ [10]. The average age of women and along with that the number of breast cancer cases will further increase. For example, in Germany the life expectancy is estimated to rise from currently 81 to 88

\begin{tabular}{ll}
\hline KARGER & @ 2008 S. Karger GmbH, Freiburg \\
$\begin{array}{l}\text { Fax +49761 4520714 } \\
\begin{array}{l}\text { E-mail Information@Karger.de } \\
\text { www.karger.com }\end{array}\end{array}$ & $\begin{array}{c}\text { Accessible online at: } \\
\text { www.karger.com/brc }\end{array}$ \\
&
\end{tabular}

Prof. Dr. med. Bernd Gerber

Universitätsfrauenklinik am Klinikum Südstadt

der Hansestadt Rostock

Südring 81, 18059 Rostock, Germany

Tel. +49 381 4401-4500, Fax -4599

E-mail bernd.gerber@med.uni-rostock.de 
years in 2050 [11]. With increasing patient age, co-morbidities and physiological aging processes influence the ability to tolerate various treatment procedures. Half of elderly patients with breast cancer are undertreated, with strongly decreased specific survival as a consequence [12]. With regard to older breast cancer patients there are no evidence-based guidelines or recommendations due to a paucity of clinical trials in this age group [13]. Earlier randomized clinical trials have mostly excluded elderly patients, mainly either on the basis of age alone, because of co-morbidities, or both [14]. According to Matti Aapro the decision for or against the local and systemic treatment depends more on the biological than the chronological age [15]. He recommends standard therapy for fit (life expectancy $>5$ years and acceptable co-morbidities) and reduced standard treatment for frail (life expectancy $<5$ years, substantial co-morbidities) elderly patients.

It is suggested that male breast cancer should be treated like female breast cancer. Christian Rudlowski describes differences between male and female patients regarding course of the disease, stages of presentation and also treatment [16]. BRCA1 and BRCA2 mutations for men are estimated to be present in $4-40 \%$ of cases and breast cancer in male patients is mostly endocrine responsive. Due to the different physiological prerequisites for estrogen production in men and women, the effect of lowering serum estrogen levels in men has not yet been scientifically validated [17]. Tamoxifen is well tolerated and has improved 5-year disease-free and overall survival. The use of aromatase inhibitors in the adjuvant setting has to be regarded as an experimental therapy at present. Adjuvant chemotherapy is associated with an improvement in diseasefree and overall survival [18]. Indications and regimens, including taxanes and trastuzumab, should be the same as in women. Finally, Toralf Reimer gives a review about rare histological types of breast tumors [19]. He separates histological types with a favorable prognosis (tubular, medullary, mucinous, and phyllodes tumors) from other specific situations like Paget's disease and inflammatory breast cancer (IBC). Patients with favorable tumors should be considered for less aggressive treatment decisions. IBC (stage cT4d) is present in the case of invasive breast cancer and clinical signs of inflammation (erythema and edema) in one third or more on the skin of the breast [2]. Stage cT4d breast cancer differs from locally advanced stages (cT4a-c) in molecular pathology, treatment, and prognosis [20,21]. In the past Paget's disease of the breast was an indication for mastectomy. According to the recommendations by T. Reimer even in Paget's disease with underlying cancer elsewhere in the breast (e.g., invasive breast cancer or DCIS) breast conserving surgery is an option.

In summary, the articles of this issue reflect the current knowledge of diagnosis and treatment in patients with malignant breast tumors in specific situations. Despite the lack of randomized clinical trials there is no justification to avoid adequate diagnostic procedures and for under- or overtreatment in such situations.

\section{References}

1 AGO: www.ago-online.org. 2008

2 NCCN (National Comprehensive Cancer Network): NCCN Practice Guidelines in Oncology: Breast Cancer. Version 2008. www.nccn.org.

3 ASCO: Clinical Practice Guidelines 2008. www. asco.org.

4 Goldhirsch A, Wood WC, Gelber RD, Coates AS Thurlimann B, Senn HJ: Progress and promise: highlights of the international expert consensus on the primary therapy of early breast cancer 2007. Ann Oncol 2007;18:1133-1144.

5 Newstead GM: MR imaging in the management of patients with breast cancer. Semin Ultrasound CT MR 2006;27:320-332.

6 Ko EY, Han BK, Shin JH, Kang SS: Breast MRI for evaluating patients with metastatic axillary lymph node and initially negative mammography and sonography. Korean J Radiol 2007;8:382-389.

7 Johansen J, Buus S, Loft A, Keiding S, Overgaard M, Hansen HS, Grau C, Bundgaard T, Kirkegaard J, Overgaard J: Prospective study of 18FDG-PET in the detection and management of patients with lymph node metastases to the neck from an unknown primary tumor. Results from the DAHAN CA-13 study. Head Neck 2007.
8 Krämer A, Hübner G, Schneeweiss A, Folprecht G, Neben K: Carcinoma of unknown primary - an orphan disease? Breast Care 2008;3:164-170.

9 Loibl S: New therapeutic options for breast cancer during pregnancy. Breast Care 2008;3:171-176.

10 Ferlay J, Bray F, Pisani P, Parkin DM, GLOBOCAN: Cancer incidence, mortality and prevalence worldwide 2002. http://www-dep.iarc.fr (2005).

11 Statistisches Bundesamt Deutschland 2008. www. destatis.de.

12 Bouchardy C, Rapiti E, Fioretta G, Laissue P, Neyroud-Caspar I, Schafer P, Kurtz J, Sappino AP, Vlastos G: Undertreatment strongly decreases prognosis of breast cancer in elderly women. J Clin Oncol 2003;21:3580-3587.

13 Wildiers H, Kunkler I, Biganzoli L, Fracheboud J, Vlastos G, Bernard-Marty C, Hurria A, Extermann M, Girre V, Brain E, Audisio RA, Bartelink H, Barton M, Giordano SH, Muss H, Aapro M: Management of breast cancer in elderly individuals: recommendations of the International Society of Geriatric Oncology. Lancet Oncol 2007;8:1101-1115.
14 Kemeny MM, Peterson BL, Kornblith AB, Muss HB, Wheeler J, Levine E, Bartlett N, Fleming G, Cohen HJ: Barriers to clinical trial participation by older women with breast cancer. J Clin Oncol 2003 ; 21:2268-2275.

15 Aapro M: Mammography screening and treatment of breast cancer in the elderly. Breast Care 2008;3 177-182.

16 Rudlowski C: Male breast cancer. Breast Care 2008:3:183-189.

17 Fentiman IS, Fourquet A, Hortobagyi GN: Male breast cancer. Lancet 2006;367:595-604.

-18 Giordano SH, Perkins GH, Broglio K, Garcia SG Middleton LP, Buzdar AU, Hortobagyi GN: Adjuvant systemic therapy for male breast carcinoma. Cancer 2005;104:2359-2364.

19 Reimer T: Management of rare histological types of breast cancer. Breast Care 2008;3:190-196.

20 Chia S, Swain SM, Byrd DR, Mankoff DA: Locally advanced and inflammatory breast cancer. J Clin Oncol 2008;26:786-790.

21 Low JA, Berman AW, Steinberg SM, Danforth DN, Lippman ME, Swain SM: Long-term follow-up for locally advanced and inflammatory breast cancer patients treated with multimodality therapy. J Clin Oncol 2004;22:4067-4074. 